\section{Investigating the effects of shyness and sociability on customer impulse buying tendencies}

\section{The moderating effect of age and gender}

\author{
Mayank Dhaundiyal \\ School of Management, Bennett University, Greater Noida, India, and \\ Joseph Coughlan \\ School of Business, Maynooth University, Maynooth, Ireland
}

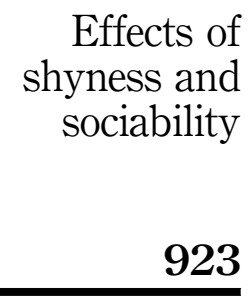

Received 17 December 2014

Revised 25 January 2015

30 October 2015

9 April 2016

2 June 2016

Accepted 30 June 2016

\begin{abstract}
Purpose - The effect of personality traits on impulse purchase is not well understood. The purpose of this paper is to investigate how two such traits, shyness and sociability, impact on impulse buying tendency. Understanding drivers of impulse purchase, a significant source of retail sales, is important to succeed in the challenging environment that store-based retailers face.

Design/methodology/approach - A customer intercept approach was taken to collect 194 responses from two locations in a busy city centre shopping street in Dublin, Ireland, and the hypotheses were tested using covariance-based structural equation modelling.

Findings - Sociability has a significant positive effect on both affective and cognitive impulse buying tendencies whereas shyness has a positive effect on cognitive impulse buying tendencies only. Age was found to be a significant moderator of these effects.

Research limitations/implications - This study uses an in vivo street-intercept approach and hence the results may differ for other data collection approaches. The lack of discriminant validity of the sub-scales for impulse buying tendencies has implications for future research.

Practical implications - The findings suggest that retailers should factor customers' psychological traits into their decision making. Individuals with high levels of sociability and shyness are prone to buying on impulse but in different ways. Younger people are more likely to exhibit these behaviours. Originality/value - This paper meets a need for research on how customers' traits affect their impulse purchase tendencies, and offers retailers advice on how to attract and serve customers with these traits.
\end{abstract}

Keywords Age, Impulse buying tendency, Sociability, Shyness

Paper type Research paper

\title{
Introduction
}

"Why won't they just leave me alone? If I need or want something I will ask!" (Mark, aged 28). Mark would assess himself as being moderately shy and is quite exasperated at store assistants who continually ask him how he is and how they can help him, to the point that he will leave the store if they approach him. In fact he notes that there are some stores he only goes to if he has to because of the level of interaction, that is "forced" on him. On the other hand, Pauline (aged 23) expects a high level of personal interaction. She states "I really like to feel that I am welcomed to the store. I always chat to the store assistants". She reveals that she enjoys the social interaction with the store assistants that she experiences while she shops, and if there is limited interaction in-store it "turns her off" the shopping experience and may result in her failing to

\footnotetext{
International Journal of Retail \& Distribution Management Vol. 44 No. 9,2016 pp. $923-939$ 1ishing Limited DOI 10.1108/IJRDM-12-2014-0166
} 
IJRDM 44,9

924 make a purchase. Mark and Pauline are typical consumers, who state that they purchase goods on impulse relatively frequently and that retailers aim to attract to their stores. However, their expectations of what they desire from a shopping experience in terms of interaction differ substantially due to their level of shyness and sociability. Interaction levels differ by channel and this paper, although cognizant of the myriad of channels open to the consumer (Beck and Rygl, 2015), focusses on the traditional retail shopping street as a context for understanding how consumers' personality traits affect their intention to purchase on impulse. The aim of this paper is to investigate the effects of shyness and sociability on impulse buying tendency (IBT).

The volume of impulse purchase is large, increasing and a significant component of retailer revenue (Jones et al., 2003; Liao et al., 2009; Xiao and Nicholson, 2013; Amos et al., 2014; Chang et al., 2014). The extant literature posits a myriad of reasons as to why individuals purchase on impulse (Amos et al., 2014) and why certain individuals have higher tendencies to purchase on impulse (Verplanken and Herabadi, 2001). The purpose of a shopping trip may include multiple tasks and can induce a mindset within the consumer that precludes or encourages impulse purchases (van Kenhove et al, 1999). Shopping mindsets are physiological processes that are dependent on the reasons why consumers make that particular shopping trip (Sarantopoulos et al., 2016). The level of abstractedness of a shopping trip (Block and Morwitz, 1999; Walters and Jamil, 2003) can influence the level of impulse buying (Bell et al., 2011).

A review of the literature demonstrates that both positive and negative affect can play a sizeable part in impulse purchase (Youn and Faber, 2000; Mohan et al., 2013; Amos et al., 2014; Chang et al., 2014). Hedonic shopping motivation is reasoned to be a predictor of impulse purchase in that consumers shop to satisfy a number of hedonic desires (Mohan et al., 2013) and therefore the actual product purchased is secondary to the main objective of satisfying the hedonic needs. Punj (2011) suggests that impulsivity is linked to variety-seeking whereas Kacen et al. (2012) acknowledge that the characteristics of the consumer are important. A significant gap in the literature is the use of personality traits to understand why some individuals are more likely to buy on impulse than others. Extant research argues that impulsivity has strong roots in people's personality (Lucas and Koff, 2014), and as a result a significant volume of research, particularly in the last decade, has focused on how psychological constructs affect impulsivity (Ayadi et al., 2013; Ozen and Engizek, 2014). Combining these two issues from the literature, and discussions with customers, led to the choice of two personality traits, that have not been tested against impulsivity in the literature before, one mainly associated with positive affect, sociability and one mainly associated with negative affect, shyness.

Hausman (2000) found that a major motive of people to go shopping is to meet and spend time with other people; thus an understanding of how sociability affects impulsivity will be of interest to retailers who aim to create a space for enjoyment of the shopping experience. Shyness is associated with multiple types of discomfort and inhibition (Amico et al., 2004). It is posited here that shy individuals will engage in impulsive purchasing in order to reduce feelings of stress and thus reward themselves for overcoming a negative emotion (Youn and Faber, 2000). Shyness is often confused with low levels of sociability (Amico et al., 2004) but this has been shown not to be the case (Cheek and Buss, 1981; Schmidt 1999; Amico et al., 2004).

The next section gives a concise overview of previous research into impulse purchase, sociability and shyness. The hypotheses are developed in this section including the moderating effects. Next, the methodology for the research is outlined. 
This is based on a questionnaire-based customer intercept survey. Findings are then reported. Finally, the discussion and conclusions section summarizes key themes that emerge from the findings, and offers recommendations for practitioners and for further research.

\section{Theoretical framework}

Based on both the psychology and the marketing literatures, a model of the proposed relationships between shyness, sociability and cognitive and affective impulse buying tendencies is developed. This paper argues that sociability and shyness are each positively associated with cognitive and affective IBT. A person with high sociability has an incentive to go to a retail store in order to meet and interact with people, to spend quality time with others, and eventually make a purchase (Plomin, 1976; Hausman 2000). Purchases may be incidental to the greater need to socialize with people. On the other hand, even though a shy individual has a lesser incentive to go to a public place to shop, it is argued that a shy individual may engage in impulse buying to reduce stress and anxiety caused due to the presence of a large number of people (Jones et al., 1986; Verplanken and Herabadi, 2001; Amos et al., 2014).

\section{Impulse purchase}

The extant literature has recognized the multifaceted (Lee and Kacen, 2008; Silvera et al., 2008; Wang and Xiao, 2009) though somewhat fragmented (Xiao and Nicholson 2013) nature of impulse purchase. Consequently, impulse buying has been looked at through various lenses. Xiao and Nicholson (2011) contend that three major disciplines via which impulse buying has been analysed are consumption impulsivity, the social and cultural dimension and through a focus on individual characteristics. Consumption impulsivity theory draws from behavioural-economic theory and argues that consumers buy on impulse with a clear lack of evaluation regarding the product and unwillingness to think about the long-term consequences (Rook, 1987) with only shortterm indulgence in mind (Liao et al., 2009; Pornpitakpan and Han, 2013).

The second group of theorists take a more external view and argue that social and cultural factors play a more significant role (Kacen and Lee, 2002; Lee and Kacen, 2008; Dittmar and Bond, 2010). These theorists contend that impulse buying is rooted in the social and cultural norms experienced through the lifetime of the individual (Wang and Xiao, 2009; Pornpitakpan and Han, 2013). Consumers buy products as a means to project self-identity and self-concept (Dittmar et al., 1995). The third group of theorists take an individual-centric view and argue that it is individual traits that ultimately decide the impulse buying activities of a consumer (Verplanken and Herabadi, 2001; Verplanken et al., 2005), the perspective taken by this paper.

Extant literature has argued that the differences between individuals in terms of psychological traits affect their impulse buying behaviour (Verplanken and Herabadi, 2001; Kacen and Lee, 2002). Consequently, this paper analyses the effects of shyness, and sociability on cognitive and affective impulse buying tendencies. In this paper Verplanken and Herabadi's (2001) categorization of impulse buying is followed. So whereas cognitive impulse buying involves lack of planning and deliberation, affective impulse buying deals with the emotional aspect (Verplanken and Herabadi, 2001). Impulse buying tends to elicit strong emotional responses (Chang et al., 2014). Consumers have been widely reported to have experienced feelings of excitement, joy, contentment and even fear during the shopping process (Li et al., 2015). 
IJRDM

44,9

926

\section{Sociability}

Sociability is the propensity of an individual to be in the company of people rather than being alone (Cheek and Buss 1981). A sociable person generally avoids being alone to the maximum extent possible and prefers to actively engage in verbal participation in a peer group conversation (Gifford and Gallagher, 1985). Having said that it is important to appreciate that sociability entails not only the number of social interactions, the quantity aspect, but also the intensity of these interactions, that is the quality aspect (Plomin, 1976). A sociable person looks forward to an opportunity to go to a shopping destination, with a key objective being meeting people. This flows from research by Arnold and Reynolds (2003) and Ganesh et al. (2007) who noted that social shopping motives are generally positive and are linked with the enjoyment of meeting and socialising with others. Hausman (2000), from a qualitative perspective, has argued that an individual's need to socialize with other people affects their impulse buying behaviour. This leads to the following hypotheses:

H1a. Sociability is related positively to cognitive IBT.

H1b. Sociability is related positively to affective IBT.

\section{Shyness}

Shyness has been defined as "discomfort and inhibition in the presence of others" (Jones et al., 1986, p. 629). It can be understood as the uneasiness and discomfort one feels in the company of other people (Cheek and Buss, 1981) and is primarily due to the interpersonal nature of the moment rather than due to feelings of danger and threat that may arise due to others presence (Jones et al., 1986). Izard (1977) in his seminal work using Differential Emotions Theory categorized shyness as a negative emotion. Shyness has been described as an excessive preoccupation with feeling and thoughts, varying between feelings of being uncomfortable to being completely reserved (Saunders and Chester, 2008). A shy individual does not act or behave in the same way as others due to the feelings of anxiety that they feel when among a group of people (Schmidt, 1999; Vertue, 2003).

Shyness has numerous negative connotations that have been widely discussed in the literature (Amico et al., 2004; Pozzulo et al., 2007; Miller et al., 2008; Saunders and Chester, 2008). Shyness has a negative effect on the information processing ability of an individual due to its adverse effect on mental performance (Pozzulo et al., 2007; Saunders and Chester, 2008) and its likelihood of increased social anxiety (Vertue, 2003). Consequently, shy individuals are likely to exhibit low levels of deliberation and planning while shopping which is directly related to the conceptualisation of cognitive IBT (Silvera et al., 2008). Gardner and Rook (1988), in an early study on impulse purchase, found that the majority of people feel better after making an impulse purchase. This is perhaps due to compensation for a stress reaction (Youn and Faber, 2000) related to having to deal with crowded retail spaces or perhaps to deal with the negative affective state shyness brings (Lucas and Koff, 2014). For a shy individual, the act of an impulse purchase is likely to have the same effect thus increasing their tendency to make future impulse purchases. Coley and Burgess (2003) note that impulse buying is partially motivated by a desire to change or manage moods which may be a reason why shy individuals, who are likely to experience negative emotions while shopping, are more likely to impulse purchase (Verplanken and Herabadi, 2001). Based on these arguments 
this paper argues that shy individuals are likely to engage in impulse buying. The hypotheses follow:

H2a. Shyness is related positively to cognitive IBT.

$H 2 b$. Shyness is related positively to affective IBT.

Moderating influence of age

Verplanken and Herabadi (2001) in their original scale development studies found age related differences in IBT with younger people having higher levels of both types of impulse buying tendencies. Kacen and Lee (2002) revealed a negative relationship between age and impulse purchase. Silvera et al. (2008) also found a negative relationship but only for the affective IBT sub-scale. Meneely et al. (2009) discovered that older consumers plan their shopping more than younger consumers. Amos et al. (2014), in a meta-analysis of the extant research, also suggested that younger people are more likely to have higher level of IBTS, though given the paucity of research, they suggest that additional research is needed on this issue:

H3a. The younger the consumer, the stronger the effect of sociability on cognitive IBT.

$H 3 b$. The younger the consumer, the stronger the effect of sociability on affective IBT.

H3c. The younger the consumer, the stronger the effect of shyness on cognitive IBT.

$H 3 d$. The younger the consumer, the stronger the effect of shyness on affective IBT.

\section{Moderating influence of gender}

Czeschlik and Nürk (1995) in a study on shyness and sociability found that males were less sociable and slightly shyer than females. This is in contrast with Bruch et al. (1989) who found females to be less sociable and also shyer than males. Extant literature has argued that females are more likely to buy on impulse than their male counterparts (Dittmar et al., 1996; Coley and Burgess, 2003; Silvera et al., 2008; Mortimer, 2012; Chang et al., 2014; Lucas and Koff, 2014). Males and females have been argued to relate differently to shopping (Teller and Thomson, 2012). A collective understanding from different studies is that males and females relate to their material possessions differently (Wallendorf and Arnould, 1988; Dittmar et al., 1995, 1996). Whereas females may be driven primarily by the product's emotional aspects (Chang et al., 2014), males tend to be driven by the functional characteristics (Mortimer, 2012). Using the Verplanken and Herabadi (2001) impulse buying tendency scale (IBTS), Silvera et al. (2008) in their study found that females had higher scores on both the cognitive as well as affective sub-scales of the IBTS:

$H 4 a$. The effect of sociability and cognitive buying tendency is stronger for female as compared to male consumers.

$H 4 b$. The effect of sociability and affective buying tendency is stronger for female as compared to male consumers.

H4c. The effect of shyness and cognitive buying tendency is stronger for female as compared to male consumers.

H4d. The effect of shyness and affective buying tendency is stronger for female as compared to male consumers. 
IJRDM 44,9

928

\section{Method}

Data collection and sample

An overview of the hypotheses is provided in Figure 1. These hypotheses were tested using a field study with consumers using an on-site (in vivo) street intercept approach. Teller's (2008) definition of a shopping street as a collection of stores on a city's main street was adopted. This method addresses the shortcomings of the in vitro approach that has traditionally been used in the academic research (Teller and Reutterer, 2008). An in vivo approach entails that data can be collected in a more realistic situation leading to deeper insights. Respondents need not try and remember the situation from prior experiences and can answer the survey questionnaire easily and more accurately. Keeping this in mind an in vivo approach was followed, and two locations in a busy city centre shopping street in Dublin Ireland were chosen for the research.

The respondents were selected randomly from the two locations. This shopping street is a major shopping location in Dublin and houses independent shops including top fashion and apparel stores, grocery chains, lifestyle and newsagents. Shoppers who were coming out from a shop were approached. The data collection was conducted over three days. A total of 204 questionnaires were collected. Out of these, ten were unusable because of a high percentage of missing data. Thus a final sample of 194 responses was used in the final study. Of these 50 per cent were males, 30 per cent were below 24 years with 36 per cent between 25 and 34 years. There were no significant differences between the responses by location or by day, for any of the measured variables, thus confirming a lack of non-response bias.

\section{Data analysis}

In order to analyse the data via structural equation modelling (SEM), a two-step approach was followed (Anderson and Gerbing 1988). First, confirmatory factor analysis (CFA) was completed for measurement validation. Second, covariance-based SEM was used to test the theoretical model using Mplus Version 7.4. This analysis technique was employed as it permits the explicit modelling of measurement error in

Figure 1.

Conceptual model

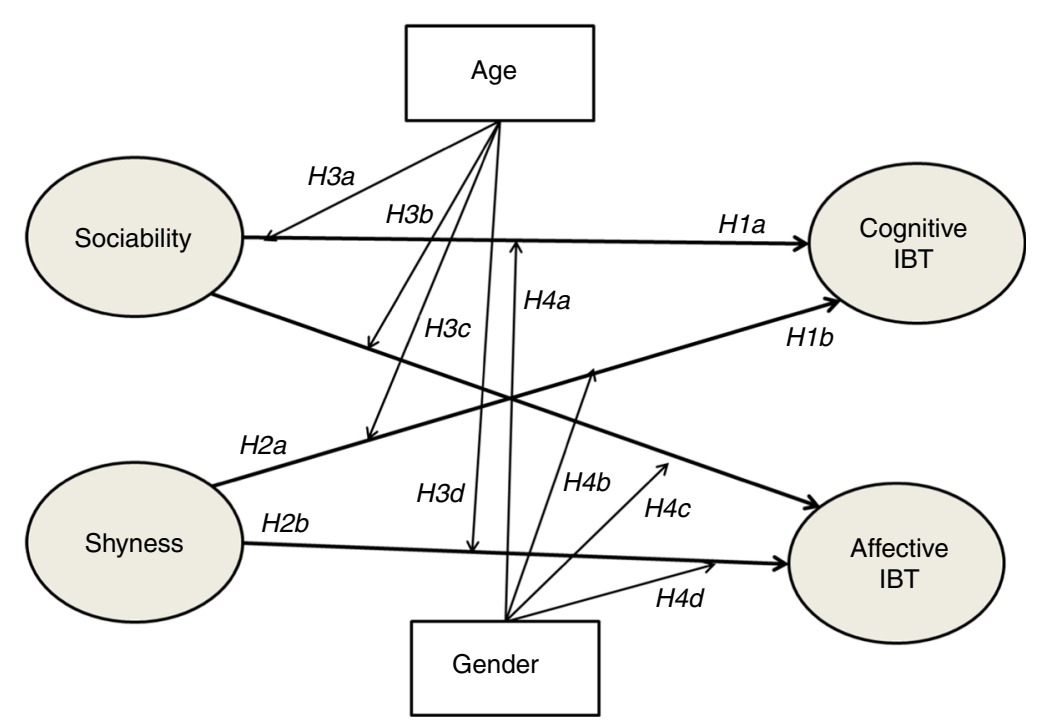


indicators of latent variables and is a confirmatory approach to theory testing (Bagozzi and $\mathrm{Yi}, 2012$ ) which permits a comprehensive means for assessing theoretical models (Anderson and Gerbing 1988). H3a-H3d and $H 4 a-H 4 d$ are moderation hypotheses and there are different options for modelling moderation. One option is to separate the group into sub-samples but given the sample size this was not feasible for both age and gender, and it can lead to potential false disconfirmation (Lam et al., 2004). The indicant product approach of Kenny and Judd (1984) was also considered but this gives rise to multiple additional variables potentially causing convergence problems. As a result we followed the Ping (1995) approach which is a simplified version of the Kenny and Judd (1984) approach.

\section{Results}

\section{Measurement}

Four constructs were measured in this study, as described below. An additional construct, hedonic motivation (Arnold and Reynolds, 2003) was also collected but could not be used as the level of discriminant validity between hedonic motivation and both forms of IBT was extremely poor. Scales for the four constructs as well as their psychometric properties are summarized in Table AI. Shyness and sociability were measured using the Cheek and Buss' (1981) scales. Impulse buying tendencies of the respondents were measured using the 20-item IBTS (Verplanken and Herabadi, 2001). The IBTS has two sub-scales, each with ten items that measure cognitive and affective impulsivity of consumers, as per Table AI. Content validity was assessed through a review of the extant literature, critical evaluation of existing constructs and their use in other studies, and a review by domain experts. The scales were all reliable with high coefficient $\alpha$ values (all above 0.880). We used CFA to assess convergent validity as suggested by O'Leary-Kelly and Vokurka (1998). Items with low reliabilities and unacceptable $R^{2}$ were removed. A measurement model for all constructs with no causal relationships and free covariance estimation between constructs was developed. This showed a good level of fit $\left(\chi^{2}=848.011\right.$, df $=489$, RMSEA $=0.062$, $\mathrm{SRMR}=0.042, \mathrm{CFI}=0.945, \mathrm{TLI}=0.941)$ providing evidence of convergent validity (O'Leary-Kelly and Vokurka, 1998). Additionally, an inspection of item loadings and correlations of all the individual constructs revealed that all factor loadings were substantial $(\geqslant 0.68)$ and significant $(p<0.001)$, and all factor correlations were significantly below unity $(p<0.001)$.

Inter-construct correlations are detailed in Table I with the square root of the AVE in the diagonal. These results indicate that convergent validity and within-construct as well as across-construct discriminant validity has been achieved (Hu and Bentler, 1999) with one major exception in terms of discriminant validity. It appears that affective and

\begin{tabular}{|c|c|c|c|c|c|}
\hline Construct & $\begin{array}{l}\text { Cognitive impulsive } \\
\text { buying tendency }\end{array}$ & $\begin{array}{l}\text { Affective impulsive } \\
\text { buying tendency }\end{array}$ & Shyness & Sociability & \\
\hline $\begin{array}{l}\text { Cognitive impulsive } \\
\text { buying tendency } \\
\text { Affective impulsive }\end{array}$ & 0.870 & 0.941 & 0.109 & 0.174 & \\
\hline $\begin{array}{l}\text { buying tendency } \\
\text { Shyness } \\
\text { Sociability }\end{array}$ & & 0.857 & $\begin{array}{l}0.131 \\
0.841\end{array}$ & $\begin{array}{r}0.092 \\
-0.133 \\
0.813\end{array}$ & $\begin{array}{r}\text { Table I. } \\
\text { Inter-construct } \\
\text { correlations }\end{array}$ \\
\hline
\end{tabular}

Effects of shyness and sociability

929 
IJRDM 44,9

930 cognitive IBT are not distinct. Prior research (Verplanken and Herabadi, 2001) also found that the two IBT scales were highly correlated but not to the extent found in this paper. However, varying results have been found in the literature when testing the different forms of IBT with other related constructs (Silvera et al., 2008; Lucas and Koff, 2014) leading to the assumption that while both are highly correlated they may not behave in the same way. Therefore to proceed with the analysis two separate models were estimated: one modelling the effects of shyness and sociability on cognitive IBT and one modelling the effects of shyness and sociability on affective IBT. Recent papers that have used Verplanken and Herabadi's (2001) conceptualisation of IBT have also proceeded with individual models for each aspect (Silvera et al., 2008; Lucas and Koff, 2014) given the high correlation between the sub-scales.

Due to the use of key informant method, the possibility of common method bias was assessed. The use of established scales and proximal separation served to reduce the risk of common method bias (Podsakoff et al., 2003, 2012). Harmon's test (Podsakoff et al., 2003) showed three distinct factors with eigenvalues at or close to 1.0, explaining 73.41 per cent of the variance. These results are acceptable as this study expects many of the constructs to be correlated in order to test a structural equation model. CFA, using a single factor, was conducted to test for common method bias (Podsakoff et al., $2012)$ and the result was a very poorly fitting model $\left(\chi^{2}=2995.487, \mathrm{df}=495\right.$, RMSEA $=0.161, \mathrm{SRMR}=0.199, \mathrm{CFI}=0.617, \mathrm{TLI}=0.592$ ) thus providing evidence for the lack of common method bias.

\section{Hypothesis testing}

Due to the issue with high correlation between the two types of IBT, the analysis proceeded in two parts following the strategies of Silvera et al. (2008) and Lucas and Koff (2014) who also had separate models for cognitive and affective IBT. The model containing cognitive IBT was tested first which included hypotheses $H 1 a, H 2 a, H 3 a$, $H 3 c, H 4 a$ and $H 4 c$. In order to model the interaction effects we took the cross-product of the means of the shyness and sociability constructs with both age and gender following the method of Ping (1995) and Robson et al. (2008). We did not see evidence of extreme multicollinearity in our data therefore we did not mean-centre our data prior to developing the interaction measures (Dawson, 2014). The level of fit for this model was very poor $\left(\chi^{2}=1699.851, \mathrm{df}=364, \mathrm{RMSEA}=0.138, \mathrm{SRMR}=0.218, \mathrm{CFI}=0.762\right.$, $\mathrm{TLI}=0.741)$.

Analysis proceeded by testing the moderators individually. $H 3 a(\beta=-0.621$, $p=0.000)$ and $H 3 c(\beta=-0.624, p=0.000)$ and were individually significant and the model fit in each case $\left(\chi^{2}=534.254, \mathrm{df}=271, \mathrm{RMSEA}=0.071, \mathrm{SRMR}=0.272\right.$, $\mathrm{CFI}=0.942$, TLI $=0.936$ for model with $H 3 a$ and $\chi^{2}=624.791, \mathrm{df}=271$, RMSEA $=0.082$, SRMR $=0.508, \mathrm{CFI}=0.923$, TLI $=0.918$ for model with $H 3 c$ ) was acceptable with the exception of a high SRMR values. Given that high factor loadings tend to lead to higher SRMR values (Anderson and Gerbing, 1984) and all other fit indices were good, the fit of these models was judged to be adequate. Figure 2 demonstrates the results of the model with only $H 3 a$ present.

The model containing affective IBT was tested next which included hypotheses $H 1 b, H 2 b, H 3 b, H 3 d, H 4 b$ and $H 4 d$. $H 2 b$ was not supported in this model its moderating effects were not tested so the model was re-run without these moderating effects. The level of fit for this model was unacceptable $\left(\chi^{2}=875.440, \mathrm{df}=293\right.$, RMSEA $=0.101$, $\mathrm{SRMR}=0.161, \mathrm{CFI}=0.869, \mathrm{TLI}=0.856)$. Analysis proceeded by testing the moderators individually. $H 3 c(\beta=-0.595, p=0.000)$ was significant and the model fit was good 


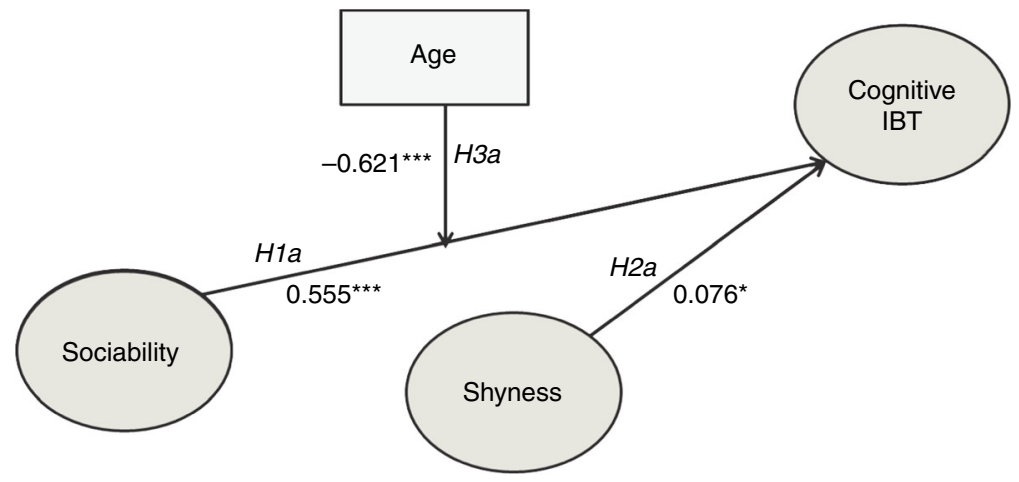

Notes: Fit statistics: $\chi^{2}=534.254 ; \mathrm{df}=271$; $\mathrm{RMSEA}=0.071$; $\mathrm{SRMR}=0.272$; $\mathrm{CFI}=0.942 ; \mathrm{TLI}=0.936$. ns, non significant. ${ }^{*} p<0.1 ;{ }^{*} p<0.05 ; * * * p<0.01$
Effects of shyness and sociability

931

Figure 2.

Empirical results for cognitive IBT model with $H 3 a$

$\left(\chi^{2}=575.919, \mathrm{df}=271, \mathrm{RMSEA}=0.076\right)$. An interesting effect was that the path between shyness and affective IBT $(H 2 b)$ became significant at the 10 per cent level $(\beta=0.096$, $p=0.052$ ). No moderating effect was found for $H 4 c$. Table II summarizes the results of the hypotheses.

\section{Discussion and conclusions}

\section{Implications for theory}

This research adds to the literature in considering how two specific customer psychological characteristics, sociability and shyness, affect the different components of impulse purchase following the stream of extant literature (Lucas and Koff, 2014; Ozen and Engizek, 2014) that considers personality traits and characteristics as integral to the discussion of what prompts impulse purchase.

An unexpected outcome of this research was the high correlation between the two facets of IBT. Due to this result, our paper modelled the two facets of IBT separately in two different models. The significant correlation of 0.87 reported in Table I is substantially higher than the scores of 0.43 and 0.54 reported by Verplanken and Herabadi (2001) in their scale development studies. Other studies in different contexts do not seem to have found such a high correlation (Verplanken et al., 2005; Silvera et al., 2008). It is notable that more recent papers such as Lucas and Koff (2014)

\begin{tabular}{|c|c|c|c|}
\hline $\mathrm{HIa}$ & Sociability $\rightarrow$ cognitive IBT & Supported & \\
\hline$H 1 b$ & Sociability $\rightarrow$ affective IBT & Supported & \\
\hline $\mathrm{H} 2 \mathrm{a}$ & Shyness $\rightarrow$ cognitive IBT & Supported & \\
\hline$H 2 b$ & Shyness $\rightarrow$ affective IBT & Not supported & \\
\hline$H 3 a$ & Moderating effect of age on $H 1 a$ & Supported & \\
\hline$H 3 b$ & Moderating effect of age on $H 1 b$ & Supported & \\
\hline$H 3 c$ & Moderating effect of age on $H 2 a$ & Supported & \\
\hline H3d & Moderating effect of age on $H 2 b$ & Not tested due to absence of main effect & \\
\hline$H 4 a$ & Moderating effect of gender on $\mathrm{HIa}$ & Not supported & \\
\hline$H 4 b$ & Moderating effect of gender on $H 1 b$ & Not supported & Table II. \\
\hline$H 4 c$ & Moderating effect of gender on $H 2 a$ & Not supported & Results of \\
\hline H4d & Moderating effect of gender on $H 2 b$ & Not tested due to absence of main effect & hypothesis testing \\
\hline
\end{tabular}


IJRDM 44,9

932 did not report a correlation and also modelled the two components separately. Our work also shows that the effects are remarkably similar between the two models we posited which is further evidence of the lack of discrimination. This raises a serious question about the discriminant validity between the two aspects of the scale developed by Verplanken and Herabadi (2001) and more work is needed to verify if the conceptualisation is indeed valid in different contexts.

Cognitive impulse buying refers to lack of planning and deliberation on the part of the consumer (Verplanken and Herabadi, 2001; Silvera et al., 2008). The strong positive and significant result of the link between sociability and cognitive IBT validates the qualitative work of Hausman (2000) and supports the findings of Zhang and Shrum (2009) who note that how individuals perceive themselves to be linked to each other has an effect on impulse purchase. The literature suggested that affective IBT is related to the emotions that consumers face (Li et al., 2015). From the results, being sociable is a trigger for emotional responses that increase the tendency to purchase on impulse validiting the results of Verplanken and Herabadi (2001). Sociability therefore has significant positive effects on both forms of IBT. People with high sociability like to meet with other people and shopping presents an excellent opportunity to do so. Therefore their propensity to purchase an item may be secondary to their primary objective being meeting people.

This research demonstrates that shyness is a weak antecedent of cognitive IBT. The possible anxiety (Schmidt, 1999; Vertue, 2003) faced by shy individuals in a retail environment may lead to a lack of planning and deliberation as their cognitive processes are overly focussed on the negative consequences of possible interaction. The literature strongly suggests that individuals may purchase on impulse to mitigate this negative affect (Coley and Burgess, 2003), however, this was not supported in this study. It seems that shyness is generally perceived as a negative state (Amico et al., 2004; Miller et al., 2008) but it does not lead to affective IBT. Strong emotional responses are not unusual in impulse purchase (Silvera et al., 2008; Li et al., 2015) and thus higher levels of shyness were expected to drive the affective tendency to purchase impulsively. The results of the analysis show that shyness has an effect on cognitive and on affective IBT though the effect size is small.

Age played an important moderating role in the analysis. Both main effects were moderated by age in the case of cognitive IBT and one effect was moderated in the case of affective IBT. This is in contrast to work by Silvera et al. (2008) who found that while age affected affective IBT, it did not have an effect on cognitive IBT. For older customers the significance of their level of sociability seems to decrease their tendency to impulse purchase on a cognitive basis vs their younger counterparts. Older people are more likely to plan their shopping (Meneely et al., 2009) suggesting that they do not engage as much in cognitive IBT as younger people. The results demonstrate that older people are better able to manage their level of shyness and are less likely to have unplanned purchases as a result of being shy. $H 3 b$ posited that the interaction effect of sociability and age would have a moderating effect on affective IBT. The results of the analysis suggest that age in combination with sociability attenuates the level of both cognitive and affective IBT, whereas age in combination with sociability only has an effect on cognitive IBT. This paper, in response to a call from Amos et al. (2014), provides a detailed exposition of the relationship between age and both forms of IBT. Gender did not have a moderating role in the model which was surprising given the significant prior outcomes in the literature (Dittmar et al., 1996; Silvera et al., 2008; Chang et al., 2014). 
In this context, a major finding of this study is that both positive (sociability) as well as negative (shyness) psychological traits affect impulse buying tendencies. Retailers therefore need to be aware of both cognitive and affective IBT. Cognitive IBT can be aided by clear advertising of product features in displays and by keeping customers aware of special offers. This is particularly important for sociable customers who would be more likely to have higher levels of both cognitive and affective IBT. They may be attracted by the opportunity to watch a demonstration shyness and sociability or to taste new products where they can meet other customers and socialize. The trend to have pop-up fashion shows in larger shopping centres is an example of how retailers are demonstrating product features and also providing an opportunity for customers to have social interactions and encourage both cognitive and affective IBT. Reminding customers of social relationships, such as family and friends, in marketing messages, can also be useful in attracting sociable individuals to stores.

Retailers can use promotional messages to establish a level of indulgence or novelty from the purchase thus appealing to customers' affective buying tendencies. Both sociable, and to a lesser extent shy, customers have higher affective IBT. Shy customers are likely to spend less time in the store therefore layout and store design are important for this category of customers. Providing adequate signage for way-finding is important for shy consumers who may not wish to socialize with other customers or staff. Retailers may need to discourage the use of standardised scripts when dealing with shy customers particularly if those scripts were focused on increasing the frequency and level of interactions with customers.

Affective impulse buying is linked to an emotional response. Policies by the retailer permitting ease of return and change of mind will reduce barriers to impulse purchase for those customers who are prone to being impulsive. Younger customers are more likely to purchase on impulse based on the results of this study thus targeting younger customers may be more beneficial for retailers who wish to increase the level of impulse purchase.

\section{Limitations and research directions}

This research is not without its limitations. First, this study uses an in vivo customer intercept approach for collecting data. Although this approach has its advantages there are several disadvantages as well (Teller and Reutterer, 2008). The findings account for a specific situation and might not be applicable for a pre-trip or post-trip view (Teller and Reutterer, 2008). Additionally the views of other people who might exert significant influence on the shopping decisions were not taken into account (Teller and Reutterer, 2008) in particular the effect of the group (Hausman, 2000), if any, that they were shopping with. The effect of shopping trip type (Walters and Jamil, 2003; Bell et al. 2011) was not considered in this research and may be another significant moderating effect on how shyness and sociability affect IBT.

Second, the data for this research was collected in a shopping street in a busy city centre location in Dublin and hence may not be generalizable to other retail agglomerations or to a same agglomeration type but at a different location. Third, our responses to the research are about IBT in general and there may be product level effects (Block and Morwitz, 1999; Kacen et al., 2012), store level effects (Lange et al., 2016), and effects based on the shopping task (van Kenhove et al., 1999). Finally, the IBTS scale as devised by Verplanken and Herabadi (2001) did not behave completely as 
IJRDM 44,9

934

expected. There was a quite high degree of correlation between the cognitive and affective impulse buying constructs, more than that found in other studies which replicated the scale (Silvera et al., 2008; Lucas and Koff, 2014). This limited the modelling choices in this paper to a significant degree.

Future research could look into hedonic shopping motivation as a predictor of impulse buying behaviour. Consumers are increasingly seeking value not only from the product but from the shopping process itself (Teller et al., 2008; Rayburn and Voss, 2013). Extant literature has argued that an individual's hedonic shopping motivations affect their impulse buying behaviour (Hausman, 2000; Park et al., 2006). Further research could also look at different groups of people such as high-shyness/ high-sociability, high-shyness/low-sociability, low-shyness/high-sociability and lowshyness/low-sociability, in order to get a further understanding of how these groups differ in their impulse buying behaviour.

The purpose of the shopping trip (Reutterer and Teller, 2009; Bell et al., 2011), or shopping mission (Sarantopoulos et al., 2016), may also have an effect on impulse purchase tendencies and behaviours. A shopper who has specific goals in mind for the shopping trip may be less likely to impulse purchase in comparison to a shopper who more abstract goals. It would be of interest to consider how the level of shyness and/or sociability affects the mindset of the shopper as they go about their shopping trip. Furthermore, the modern consumer uses multiple channels to shop and multi-channel retailing is commonplace (Beck and Rygl, 2015). Following from Dennis et al. (2016) who considered the use of multiple retail channels by those who are socially excluded, a future research project could consider if the level of shyness could also impact on multi-channel use, given that individuals with higher levels of shyness tend to have increased social anxiety (Vertue, 2003). It is likely that individuals with high degrees of shyness may prefer non-face-to-face retail channels whereas those with higher levels of sociability may prefer more traditional channels.

Finally this research has focused purely on the antecedent phase of impulse purchase (Xiao and Nicholson, 2011). It would be interesting to follow the sequence through into the act of purchase and the post-purchase stages in particular and consider how satisfaction is affected by the levels of sociability and shyness traits at customer level. Of significant interest is the incidence and level of customers returning goods purchased on impulse to retailers and the link to the personality traits at the antecedent phase.

\section{References}

Amico, K.R., Bruch, M.A., Haase, R.F. and Sturmer, P.J. (2004), "Trait shyness, actual-ought self-discrepancy and discomfort in social interaction", Personality and Individual Differences, Vol. 36 No. 7, pp. 1597-1610.

Amos, C., Holmes, G. and Keneson, W. (2014), "A meta-analysis of consumer impulse buying”, Journal of Retailing and Consumer Services, Vol. 21 No. 2, pp. 86-97.

Anderson, J.C. and Gerbing, D.W. (1984), “The effect of sampling error on convergence, improper solutions, and goodness-of-fit indices for maximum likelihood confirmatory factor analysis", Psychometrika, Vol. 49 No. 2, pp. 155-173.

Anderson, J.C. and Gerbing, D.W. (1988), "Structural equation modeling in practice: a review and recommended two-step approach", Psychological Bulletin, Vol. 103 No. 3, pp. 411-423.

Arnold, M.J. and Reynolds, K.E. (2003), "Hedonic shopping motivations", Journal of Retailing, Vol. 79 No. 2, pp. 77-95. 
Ayadi, N., Giraud, M. and Gonzalez, C. (2013), "An investigation of consumers' self-control mechanisms when confronted with repeated purchase temptations: evidence from online private sales", Journal of Retailing and Consumer Services, Vol. 20 No. 3, pp. 272-281.

Bagozzi, R.P. and Yi, Y. (2012), "Specification, evaluation, and interpretation of structural equation models", Journal of the Academy of Marketing Science, Vol. 40 No. 1, pp. 8-34.

Beck, N. and Rygl, D. (2015), "Categorization of multiple channel retailing in multi-, cross-, and omni-channel retailing for retailers and retailing", Journal of Retailing and Consumer Services, Vol. 27, pp. 170-178.

Bell, D.R., Corsten, D. and Knox, G. (2011), "From point of purchase to path to purchase: how preshopping factors drive unplanned buying", Journal of Marketing, Vol. 75 No. 1, pp. 31-45.

Block, L.G. and Morwitz., V.G. (1999), "Shopping lists as an external memory aid for grocery shopping: influences on list writing and list fulfillment", Journal of Consumer Psychology, Vol. 8 No. 4, pp. 343-375.

Bruch, M.A., Gorsky, J.M., Collins, T.M. and Berger, P.A. (1989), "Shyness and sociability reexamined: a multicomponent analysis", Journal of Personality and Social Psychology, Vol. 57 No. 5, pp. 904-915.

Chang, H.J., Yan, R.-N. and Eckman, M. (2014), "Moderating effects of situational characteristics on impulse buying”, International Journal of Retail \& Distribution Management, Vol. 42 No. 4, pp. 289-314.

Cheek, J.M. and Buss, H.A. (1981), "Shyness and sociability", Journal of Personality and Social Psychology, Vol. 41 No. 2, pp. 330-339.

Coley, A. and Burgess, B. (2003), "Gender differences in cognitive and affective impulse buying”, Journal of Fashion Marketing and Management, Vol. 7 No. 3, pp. 282-295.

Czeschlik, T. and Nürk, H-C (1995), "Shyness and sociability: factor structure in a German sample", European Journal of Psychological Assessment, Vol. 11 No. 2, pp. 122-127.

Dawson, J.F. (2014), "Moderation in management research: what, why, when and how", Journal of Business Psychology, Vol. 29 No. 1, pp. 1-19.

Dennis, C., Alamanos, E., Papagiannidis, S. and Bourlakis, M. (2016), "Does social exclusion influence multiple channel use? The interconnections with community, happiness, and well-being", Journal of Business Research, Vol. 69 No. 3, pp. 1061-1070.

Dittmar, H. and Bond, R. (2010), "I want it and I want it now: using a temporal discounting paradigm to examine predictors of consumer impulsivity”, British Journal of Psychology, Vol. 101 No. 4, pp. 751-776.

Dittmar, H., Beattie, J. and Friese, S. (1995), "Gender identity and material symbols: objects and decision considerations in impulse purchases", Journal of Economic Psychology and Health, Vol. 16 No. 3, pp. 491-511.

Dittmar, H., Beattie, J. and Friese, S. (1996), "Objects, decision considerations and selfimage in men's and women's impulse purchases”, Acta Psychologica, Vol. 93 Nos 1-3, pp. 187-206.

Ganesh, J., Reynolds, K.E. and Luckett, M.G. (2007), "Retail patronage behavior and shopper typologies: a replication and extension using a multi-format, multi-method approach", Journal of the Academy of Marketing Science, Vol. 35 No. 3, pp. 369-381.

Gardner, M.P. and Rook, D.W. (1988), "Effects of impulse purchases on consumers' affective states", Advances in Consumer Research, Vol. 15 No. 1, pp. 127-130. 
IJRDM 44,9

936

Gifford, R. and Gallagher, T.M.B. (1985), "Sociability: personality, social context and physical setting", Journal of Personality and Social Psychology, Vol. 48 No. 4, pp. 1015-1023.

Hausman, A. (2000), "A multi-method investigation of consumer motivations in impulse buying behavior", Journal of Consumer Marketing, Vol. 17 No. 5, pp. 403-426.

Hu, L.-T. and Bentler, P.M. (1999), "Cutoff criteria for fit indexes in covariance structure analysis: conventional criteria versus new alternatives", Structural Equation Modeling: A Multidisciplinary Journal, Vol. 6 No. 1, pp. 1-55.

Izard, C.E. (1977), Human Emotions, Plenum, New York, NY.

Jones, M.A., Reynolds, K.E., Weun, S. and Beatty, S.E. (2003), "The product-specific nature of impulse buying tendency", Journal of Business Research, Vol. 56 No. 7, pp. 505-511.

Jones, W.H., Briggs, S. and Smith, T. (1986), "Shyness: conceptualization and measurement", Journal of Personality and Social Psychology, Vol. 51 No. 3, pp. 629-639.

Kacen, J.J. and Lee, J.A. (2002), "The Influence of culture on consumer impulsive buying behavior", Journal of Consumer Psychology, Vol. 12 No. 2, pp. 163-176.

Kacen, J.J., Hess, J.D. and Walker, D. (2012), "Spontaneous selection: the influence of product and retailing factors on consumer impulse purchases", Journal of Retailing and Consumer Services, Vol. 19 No. 6, pp. 578-588.

Kenny, D. and Judd, C.M. (1984), "Estimating the nonlinear and interactive effects of latent variables”, Psychological Bulletin, Vol. 96 No. 1, pp. 201-210.

Lam, S.Y., Shankar, V., Erramilli, M.K. and Murthy, B. (2004), "Customer value, satisfaction, loyalty, and switching costs: an illustration from a business-to-business service context", Journal of the Academy of Marketing Science, Vol. 32 No. 3, pp. 293-311.

Lange, F., Rosengren, S. and Blom, A. (2016), "Store-window creativity's impact on shopper behavior", Journal of Business Research, Vol. 69 No. 3, pp. 1014-1021.

Lee, J.A. and Kacen, J.J. (2008), "Cultural influences on consumer satisfaction with impulse and planned purchase decisions", Journal of Business Research, Vol. 61 No. 3, pp. 265-272.

Li, Z., Deng, S. and Moutinho, L. (2015), "The impact of experience activities on tourist impulse buying: an empirical study in China”, Asia Pacific Journal of Tourism Research, Vol. 20 No. 2, pp. 191-209.

Liao, S.-L., Shen, Y.-C. and Chu, C.-H. (2009), "The effects of sales promotion strategy, product appeal and consumer traits on reminder impulse buying behaviour", International Journal of Consumer Studies, Vol. 33 No. 3, pp. 274-284.

Lucas, M. and Koff, E. (2014), "The role of impulsivity and of self-perceived attractiveness in impulse buying in women", Personality and Individual Differences, Vol. 56 No. 1, pp. 111-115.

Meneely, L., Burns, A. and Strugnell, C. (2009), "Age associated changes in older consumers retail behaviour”, International Journal of Retail \& Distribution Management, Vol. 37 No. 12, pp. 1041-1056.

Miller, J.L., Schmidt, L.A. and Vaillancourt, T. (2008), "Shyness, sociability, and eating problems in a non-clinical sample of female undergraduates", Eating Behaviors, Vol. 9 No. 3, pp. 352-359.

Mohan, G., Sivakumaran, B. and Sharma, P. (2013), "Impact of store environment on impulse buying behavior", European Journal of Marketing, Vol. 47 No. 10, pp. 1711-1732. 
Mortimer, G. (2012), "Toward a shopping typology of primary male grocery shoppers", International Journal of Retail \& Distribution Management, Vol. 40 No. 10, pp. $790-810$.

O'Leary-Kelly, S.W. and Vokurka, R.J. (1998), “The empirical assessment of construct validity”, Journal of Operations Management, Vol. 16 No. 4, pp. 387-405.

Ozen, H. and Engizek, N. (2014), "Shopping online without thinking: being emotional or rational?", Asia Pacific Journal of Marketing and Logistics, Vol. 26 No. 1, pp. 78-93.

Park, E.J., Kim, E.Y. and Forney, J.C. (2006), "A structural model of fashion-oriented impulse buying behavior", Journal of Fashion Marketing \& Management, Vol. 10 No. 4, pp. 433-446.

Ping, R.A. (1995), “A parsimonious estimation technique for interaction and quadratic latent variables”, Journal of Marketing Research, Vol. 32 No. 3, pp. 336-347.

Plomin, R. (1976), "Extraversion: sociability and impulsivity?”, Journal of Personality Assessment, Vol. 40 No. 1, pp. 24-30.

Podsakoff, P.M., MacKensie, S.B. and Podsakoff, N.P. (2012), "Sources of method bias in social science research and recommendations on how to control it", Annual Review of Psychology, Vol. 63, pp. 539-569.

Podsakoff, P.M., MacKensie, S.B., Lee, J.-Y. and Podsakoff, N.P. (2003), “Common method biases in behavioral research: a critical review of the literature and recommended remedies", Journal of Applied Psychology, Vol. 88 No. 5, pp. 879-903.

Pornpitakpan, C. and Han, J.H. (2013), "The effect of culture and salespersons' retail service quality on impulse buying", Australasian Marketing Journal, Vol. 21 No. 2, pp. 85-93.

Pozzulo, J.D., Crescini, C., Lemieux, J.M.T. and Tawfik, A. (2007), "The effect of shyness on eyewitness memory and the susceptibility to misinformation", Personality and Individual Differences, Vol. 43 No. 7, pp. 1656-1666.

Punj, G. (2011), "Impulse buying and variety seeking: simliarities and differences", Journal of Business Research, Vol. 64 No. 7, pp. 745-748.

Rayburn, S.W. and Voss, K.E. (2013), “A model of consumer's retail atmosphere perceptions”, Journal of Retailing and Consumer Services, Vol. 20 No. 4, pp. 400-407.

Reutterer, T. and Teller, C. (2009), "Store format choice and shopping trip types", International Journal of Retail \& Distribution Management, Vol. 37 No. 8, pp. 695-710.

Robson, M.J., Katsikeas, C.S. and Bello, D.C. (2008), "Drivers and performance outcomes of trust in international strategic alliances: the role of organizational complexity", Organization Science, Vol. 19 No. 4, pp. 647-655.

Rook, D.W. (1987), "The buying impulse”, Journal of Consumer Research, Vol. 14 No. 2, pp. 189-199.

Sarantopoulos, P., Theotokis, A., Pramatari, K. and Doukidis., G. (2016), "Shopping missions: an analytical method for the identification of shopper need states", Journal of Business Research, Vol. 69 No. 3, pp. 1043-1052.

Saunders, P.L. and Chester, A. (2008), "Shyness and the internet: social problem or panacea?", Computers in Human Behavior, Vol. 24 No. 6, pp. 2649-2658.

Schmidt, L.A. (1999), "Frontal brain electrical activity in shyness and sociability", Psychological Science, Vol. 10 No. 4, pp. 316-320.

Silvera, D., Lavack, A. and Kropp, F. (2008), "Impulse buying: the role of affect, social influence, and subjective wellbeing”, Journal of Consumer Marketing, Vol. 25 No. 1, pp. 23-33.

\section{Effects of shyness and sociability}


IJRDM 44,9

938

Teller, C. (2008), "Shopping streets versus shopping malls - determinants of agglomeration format attractiveness from the consumers' point of view", The International Review of Retail, Distribution and Consumer Research, Vol. 18 No. 4, pp. 381-403.

Teller, C. and Thomson, J.A. (2012), "Gender differences of shoppers in the marketing and management of retail agglomerations", Services Industries Journal, Vol. 32 No. 6, pp. $961-980$.

Teller, C. and Reutterer, T. (2008), "The evolving concept of retail attractiveness: what makes retail agglomerations attractive when customers shop at them?", Journal of Retailing and Consumer Services, Vol. 15 No. 3, pp. 127-143.

Teller, C., Reutterer, T. and Schnedlitz, P. (2008), "Hedonic and utilitarian shopper types in evolved and created retail agglomerations", International Review of Retail, Distribution \& Consumer Research, Vol. 18 No. 3, pp. 283-309.

van Kenhove, P., de Wulf, K. and van Waterschoot, W. (1999), "The impact of task definition on store-attribute saliences and store choice", Journal of Retailing, Vol. 75 No. 1, pp. 125-137.

Verplanken, B. and Herabadi, A.G. (2001), "Individual differences in impulse buying tendency: feeling and no thinking”, European Journal of Personality, Vol. 15 No. S1, pp. S71-S83.

Verplanken, B., Herabadi, A.G., Perry, J.A. and Silvera, D.H. (2005), “Consumer style and health: the role of impulsive buying in unhealthy eating", Psychology \& Health, Vol. 20 No. 4, pp. 429-441.

Vertue, F.M. (2003), "From adaptive emotion to dysfunction: an attachment perspective on social anxiety disorder", Personality and Social Psychology Review, Vol. 7 No. 2, pp. 170-191.

Wallendorf, M. and Arnould, E. (1988), "My favourite things: a cross cultural enquiry into object attachment, possessiveness, and social linkage", Journal of Consumer Research, Vol. 14 No. 4, pp. 531-547.

Walters, R.G. and Jamil, M. (2003), "Exploring the relationships between shopping trip type, purchases of products on promotion, and shopping basket profit", Journal of Business Research, Vol. 56 No. 1, pp. 17-29.

Wang, J. and Xiao, J.J. (2009), "Buying behavior, social support and credit card indebtedness of college students”, International Journal of Consumer Studies, Vol. 33 No. 1, pp. 2-10.

Xiao, S.H. and Nicholson, M. (2011), "Mapping impulse buying: a behaviour analysis framework for services marketing and consumer research", Service Industries Journal, Vol. 31 No. 15, pp. 2515-2528.

Xiao, S.H. and Nicholson, M. (2013), "A Multidisciplinary cognitive behavioural framework of impulse buying: a systematic review of the literature", International Journal of Management Reviews, Vol. 15 No. 3, pp. 333-356.

Youn, S. and Faber, R.J. (2000), "Impulse buying: its relation to personality traits and cues", Advances in Consumer Research, Vol. 27, pp. 179-185.

Zhang, Y. and Shrum, L.J. (2009), "The influence of self-construal on impulsive consumption”, Journa of Consumer Research, Vol. 35 No. 5, pp. 838-850. 
Appendix

Cognitive IBT (Cronbach $\alpha=0.969, C R=0.969, A V E=0.757$ )

I usually think carefully before I buy something

I usually only buy things that I intended to buy

If I buy something, I usually do that spontaneously

Most of my purchases are planned in advance

I only buy things that I really need

It is not my style to just buy things

I like to compare different brands before I buy one

Before I buy something I always carefully consider whether I need it

I am used to buying things "on the spot"

I often buy things without thinking

Affective IBT (Cronbach $\alpha=0.961, C R=0.961, A V E=0.734$ )

It is a struggle to leave nice things I see in a shop

I sometimes cannot suppress the feeling of wanting to buy something

I sometimes feel guilty after having bought something

I'm not the kind of person who 'falls in love at first sight' with things I see in shops

I can become very excited if I see something I would like to buy

I always see something nice whenever I pass by shops

I find it difficult to pass up a bargain

If I see something new, I want to buy it

I am a bit reckless in buying things

I sometimes buy things because I like buying things, rather than because I need them

Shyness (Cronbach $\alpha=0.955, C R=0.956, A V E=0.708$ )

I am socially somewhat awkward

I do not find it hard to talk to strangers

I feel tense when I'm with people I do not know well

When conversing I worry about saying something dumb

I feel nervous when speaking to someone in authority

I am often uncomfortable at parties and other social functions

I feel inhibited in social situations

I have trouble looking someone right in the eye

I am more shy with members of the opposite sex

Sociability (Cronbach $\alpha=0.885, C R=0.886, A V E=0.610$ )

I like to be with people

I welcome the opportunity to mix socially with people

I prefer working with others rather than alone

I find people more stimulating than anything else

I'd be unhappy if I were prevented from making many social contacts
0.910

0.890

0.875

0.874

0.817

0.854

0.860

0.916

0.832

0.867

0.839

0.879

0.847

$0 . \overline{852}$

0.910

0.846

0.844

0.821

0.867

0.878

0.806

0.878

0.854

0.819

0.853

0.832

0.821

0.831

0.831
Effects of

shyness and

sociability

939

\section{Corresponding author}

Mayank Dhaundiyal can be contacted at: mayank.dhaundiyal@gmail.com

For instructions on how to order reprints of this article, please visit our website:

www.emeraldgrouppublishing.com/licensing/reprints.htm

Or contact us for further details: permissions@emeraldinsight.com 